\title{
THE USE OF THE DRASTIC METHOD AND GIS IN ASSEESSING THE VULNERABILITY OF THE GROUNDWATER, IN THE VELIPOJA -ZADRIMA AQUIFER, ALBANIA
}

\author{
Bele S. \\ Polytechnic University of Tirana, Geological Faculty of Mining, Geoinformation Department, \\ Tirana, Albania,bele.s@hotmail.com
}

\begin{abstract}
The Albanian plain area is densely populated. The population doubled during the last two decades and most of it uses the groundwaters of these aquifers. Aquifers in lowland areas are vulnerable to pollution. This article assesses the vulnerability of groundwater Velipoj-Zadrimè aquifer. This aquifer has a surface of $237 \mathrm{~km}^{2}$ and an average height of $10 \mathrm{~m}$ above sea level. Groundwater recourses are connected with alluvial deposits formed by Drini and Buna rivers. The vulnerability Map is an important tool for the management of the territory. It guides the selection of areas for development projects, in order to avoid negative consequences on the quality of groundwater. Geographic Information Systems are very valuable programme for processing. The DRASTIC method has been used to map the natural aquifer vulnerability of the Velipoja-Zadrima study area. This method, applied to assess the vulnerability of the aquifer, was developed by the "Environmental Protection Agency (US EPA)" and "The National Association of Water Wells (NWWA)". It is a technique to assess the potential contamination of groundwater and is based on seven (7) parameters: Depth (D), Recharge (R), Aquifer media (A), Soil media (S), Topography (T), Impact of vadose zone (I), and Conductivity of the aquifer $(C)$. The DRASTIC index is determined by the sum of the products of the Weight and site ratings of all the parameters. High values of vulnerability cover large areas of the aquifer. The results provide important information for local authorities in the management of resources and territory.
\end{abstract}

Keywords: Map, groundwater, management.

\section{Introduction}

In the past two decades there has been a great population influx in the lowland and coastal areas, increasing need to use good quality water and agricultural products. This has especially led to increased exploitation rates of groundwater. Groundwater in coastal and lowland aquifers in Albania is under anthropogenic pressure (Beshku, 2012b). The most efficient method to combat groundwater pollution remains initial prevention. Initial concepts for the vulnerability of aquifers from external pollutants are provided by Margat in 1968, followed by many other authors (Aller et al., 1987; Civita, 1994; Vrba and Zaporozec, 1994; Sener et al., 2009; Voudouris et al., 2010).

This article addresses the natural vulnerability of groundwater in the porous aquifer of VelipojeZadrime located in northwestern Albania. The data is based on hydrogeological surveys and studies that include data on aquifer lithology, food and its hydraulic properties (Gjata et al., 1964; Babameto, 
1968; Tyli, 1988; Gelaj, et al., 2001; Beshku, 2012). The vulnerability Map that is presented is based on the DRASTIC method in GIS context.

\section{Description of the study area}

The Velipoja-Zadrima aquifer lies in the northwest part of Albania, bordered on the north and west respectively by Drini and Buna rivers and covers an area of $237 \mathrm{~km}^{2}$ (Figure 1).

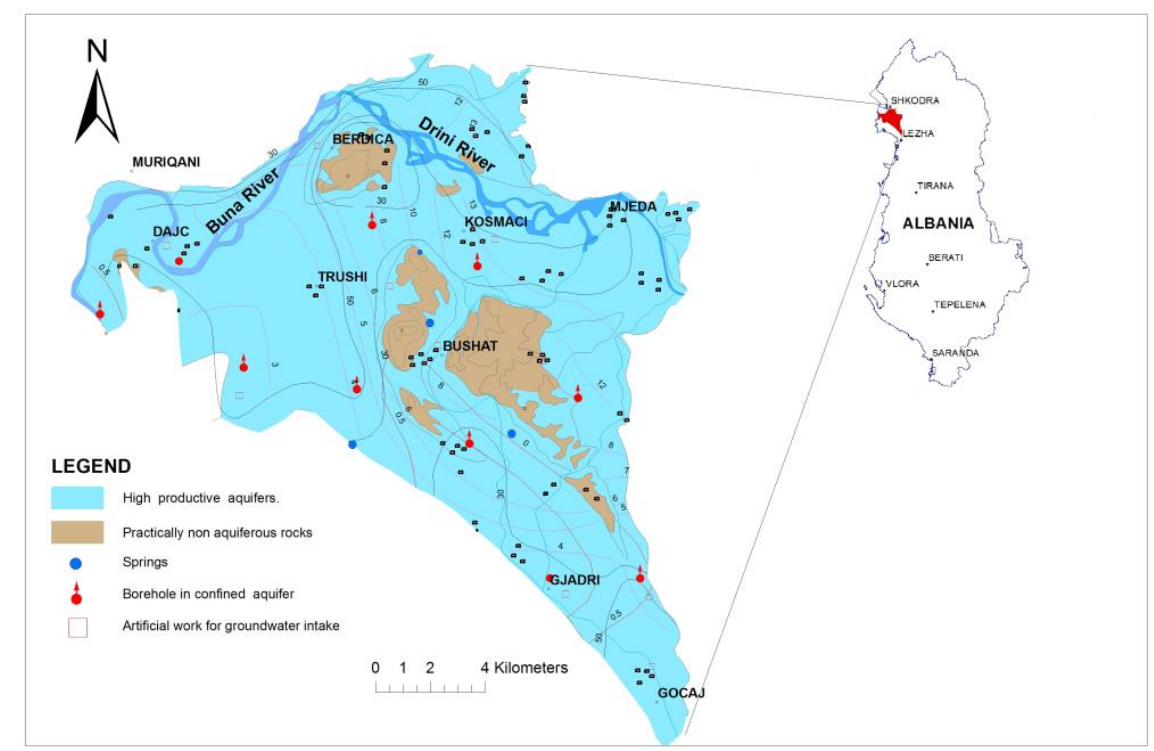

Figure 1 - Hydrogeological schematic map and the area under study.

The most important economic activities in the area are tourism and agriculture. The region is characterized by hot dry summers and mild rainy winters. Annual mean air temperature ranges is $15^{\circ} \mathrm{C}$ (Inst. Of Hydrometeorology, 1975). Annual mean precipitations vary from $1,800 \mathrm{~mm}$ in the north part of the aquifer to $1650 \mathrm{~mm}$ in the southeast part (Pano, 2008).

From a geological view, Quaternary Deposits are common in the area. They are characterized by Pleistocene-Holocene alluvial-prolluvial mixed deposits and Holocene alluvial, marsh - lake lagoon sediments. These alluvial sediments are composed of sands, gravels, and siltstones which are found along the stream flows and their mouths. Alluvial deposits extend into the plain areas. They are at the surface from Drini River in the northeast to Gjymti Mountain in southwest and in the Zadrima plain as well (Xhomo et. al., 2002; Hoxha et al., 2009).

The nature and geometry of the aquifer is related to the river Fan, and littoral and marine environment development. In addition, the pre Quaternary paleo relief and in particular the Renci structure extension played an important role in its development (Durmishi et al., 2005).

The groundwater resources are concentrated in gravel and sand sediments. For the most part, silt and sand overlap the water bearing gravels (Figure 2).

In general, the thickness of the cover in the southwestern direction. The variation of the cover thickness over the area ranges from 4 to $10 \mathrm{~m}$ nearby Drini River. In the central part of the Velipoja plain, its thickness goes up to 20-30 m. From a hydrogeological point of view, the Velipoja-Zadrima plain may be characterized as a sub artesian aquifer the Trushi Poshtem sector is artesian in nature; and the Drini River margin displays a free surface. 


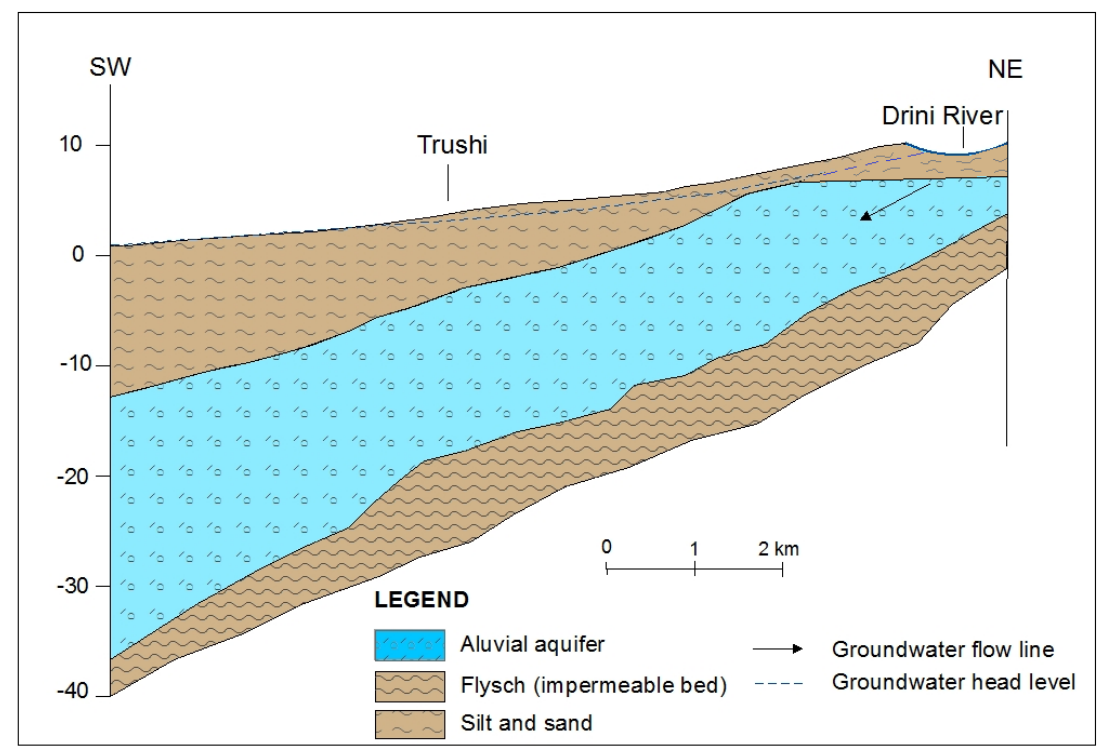

Figure 2 - Hydrogeological schematic cross section by A.G.S. (Albanian Geological Service) with modification.

\section{Assessing the vulnerability of groundwater with the DRASTIC method}

The concept of groundwater vulnerability is based on the assumption that the physical environment performs to some extent the protection of groundwater. Natural vulnerability is a very important feature of the aquifer (Vrba and Zaporozec, 1994).

In this study natural vulnerability is calculated using the DRASTIC method. It is a method used to identify areas where groundwater is more or less susceptible to impact from pollution.

The DRASTIC model consists of seven hydrogeological parameters that have weighted averages assigned. The seven parameters evaluated in the model are: Depth, Recharge, Aquifer media, Soil media, Topography, Impact of vadose zone media and hydraulic Conductivity of the aquifer.

For determining the DRASTIC index (DI) every parameter is evaluated by a value, which ranges from 1 (lowest potential pollutants) to 10 (highest potential pollutants), depending on the conditions of the area. Each parameter is also assessed according to the relative weight of each factor with a range from 1 to 5 (Table 1$)$.

Table 1 - Relative weights given to the DRASTIC parameters (Aller et al., 1987).

\begin{tabular}{|l|l|c|}
\hline \multicolumn{2}{|c|}{ Parameters } & $\begin{array}{c}\text { DRASTIC Weight } \\
\text { (typical) }\end{array}$ \\
\hline D & Depth & 5 \\
\hline R & Recharge & 4 \\
\hline A & Aquifer media & 3 \\
\hline S & Soil media & 2 \\
\hline T & Topography & 1 \\
\hline I & Impact of vadose zone media & 5 \\
\hline C & Hydraulic Conductivity of the aquifer & 3 \\
\hline
\end{tabular}


The DRASTIC method makes four assumptions:

1. Contamination is introduced at the ground surface

2. Contamination is flushed into the groundwater by precipitation

3. Contamination has the mobility of water

4. Area being evaluated is 100 -acres or larger

The values of the parameters used for the implementation of this method are based on monitoring data, field work, data for measuring levels, pumping test data and soil analysis. The mapping of the DRASTIC index is made in the vector mode using the interpolation techniques IDW ARC MAP 10.3. This creates a database in which all data recorded in a common coordinate system, resulting in the production of thematic maps of the vulnerability in the study area after processing.

\section{Results}

\subsection{Model Parameters}

\subsubsection{Depth to groundwater (D)}

The determination of the variable $\mathrm{D}$ (Depth to water table) values is made from the piezometric map (Beshku et al., 2014). The depth of groundwater varies from $2 \mathrm{~m}$ to over $31 \mathrm{~m}$ (Figure 3).

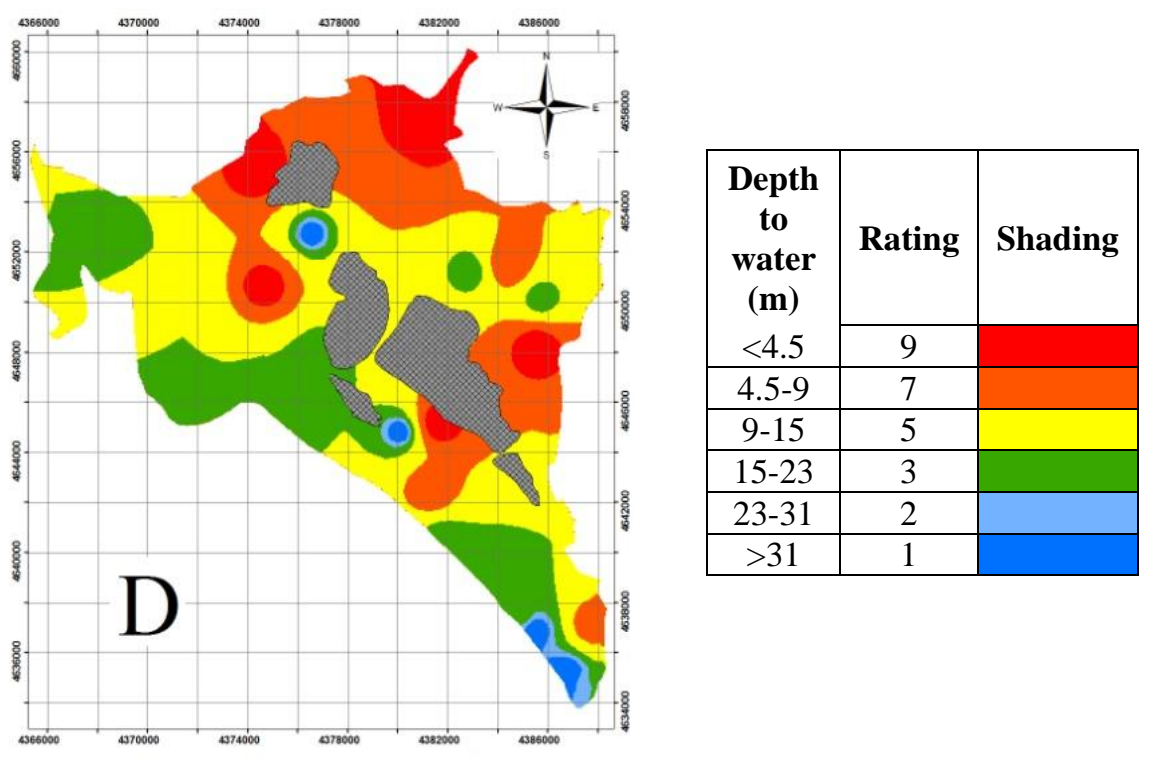

Figure 3 - Depth to groundwater rating map.

\subsubsection{Net Recharge $(R)$}

Aquifer feeding represents the total amount of water that infiltrates from the surface to the aquifer in a year. It plays an important role in the transport of pollutants from rainfall that infiltrate the vadose zone.

The variable $\mathrm{R}$ is calculated from precipitation data (Pano, 2008) and infiltration coefficients of geological formations. Depending on the type of soil and lithology, the amount of water that infiltrates into the aquifer, generally ranges from $10 \%$ to $20 \%$ of the annual precipitation. On this 
basis, net feed in the study area varies from $160 \mathrm{~mm}$ to $480 \mathrm{~mm}$. The net annual food thematic map of the aquifer is shown in Figure 4.

\subsubsection{Aquifer media (A)}

The environmental aquifer assessment is done based on the hydrogeological map and drilling carried out (Gjata et al., 1965; Keta et al., 1988). Based on this information the aquifer environment is composed only of gravel. Figure 3 presents the environmental thematic aquifer map.

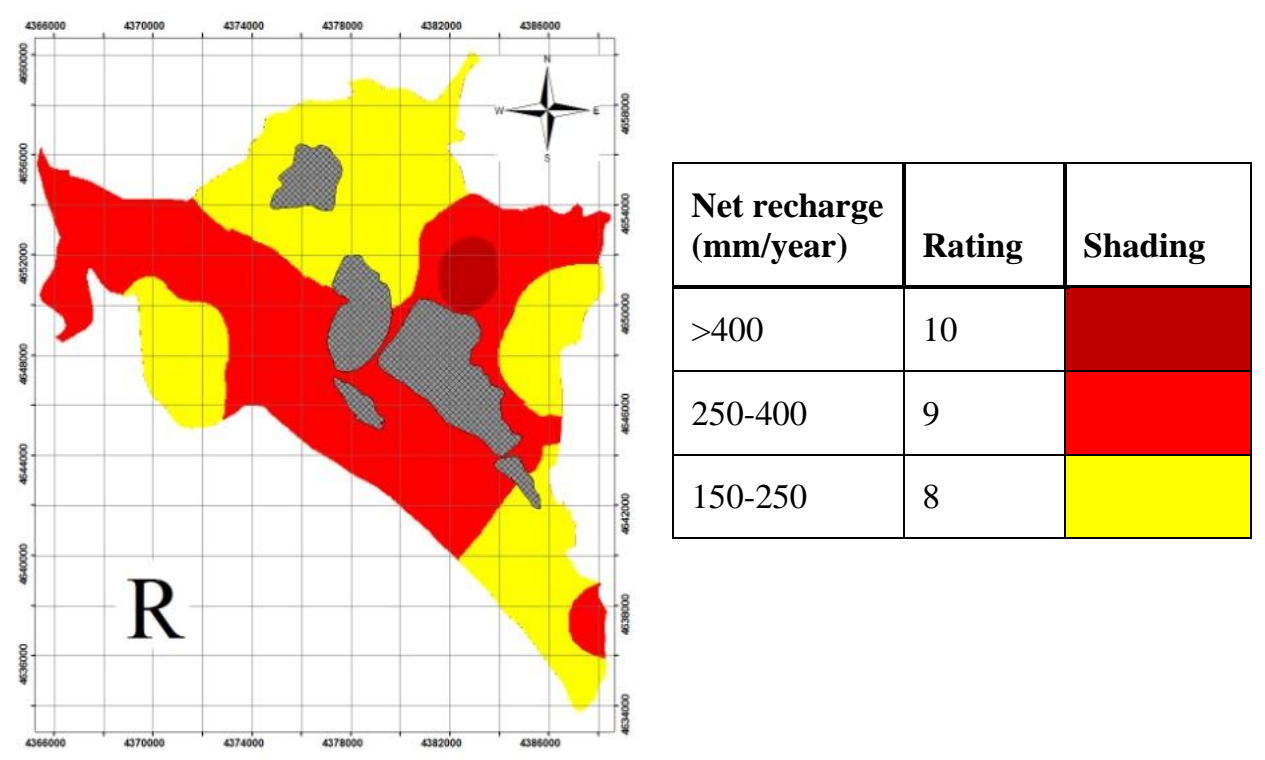

Figure 4 - Net annual recharge rating map.

\subsubsection{Soil media (S)}

The role of the land environment factor plays a major role in the net feeding of the aquifer. The presence of fine grained environment reduces infiltration, therefore reducing the potential pollutants and vice versa. Figure 5 presents the soil types that predominate in the study area:

- Medium textured

- Fine textured

- Very fine textured

\subsubsection{Topography (T)}

Variable $\mathrm{T}$ (Topography) is determined by the construction of digital terrain model. This parameter is important, as it relates to the possibility that pollutants are either carried by surface flow or infiltrate the aquifer.

The topography of the Velipoja-Zadrima aquifer is flat and the slope is under $2 \%$. The thematic map of the terrain slope is shown in Figure 5.

\subsubsection{Impact of the vadose zone (I)}

The unsaturated zone includes the area under the ground environment that reaches up to the level of groundwater. It plays an important role in the filtering of rainfall and surface flow. The characteristics of this area are associated the concentrations of pollutants associated with improvement of the structure, mineral composition and the organic material contained. 
The variable rating is based on data taken from the reports of hydrogeological drilling (Gjata $e t$ al., 1965; Keta et al., 1988). The vadose zone in the study area is comprised of non-cemented gravel, clay mixture, sands of gravel and clay. Figure 5 shows the impact thematic map of the vadose area.

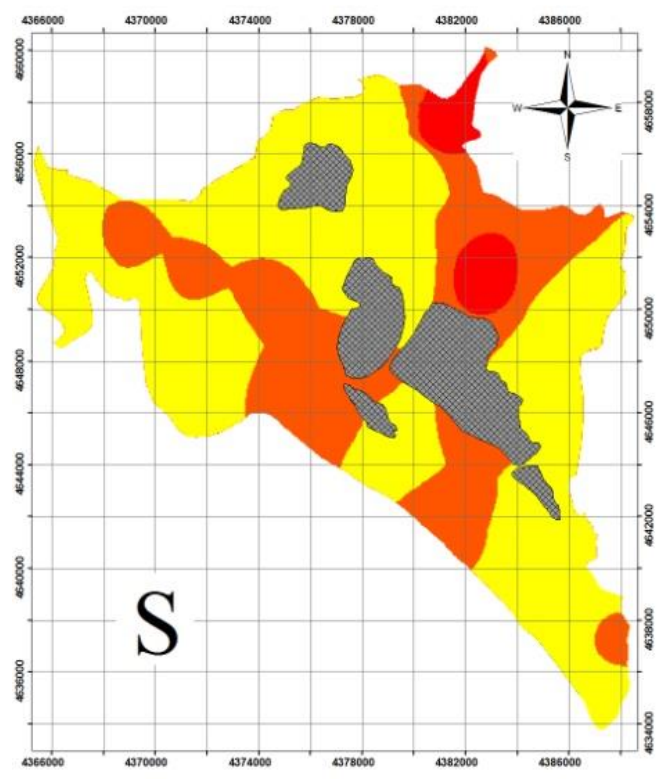

\begin{tabular}{|l|l|l|}
\hline \multicolumn{1}{|c|}{ Soil media } & Rating & Shading \\
\hline Medium textured & 8 & \\
\hline Fine textured & 6 & \\
\hline Very fine textured & 4 & \\
\hline
\end{tabular}

Figure 5 - Soil media rating map.

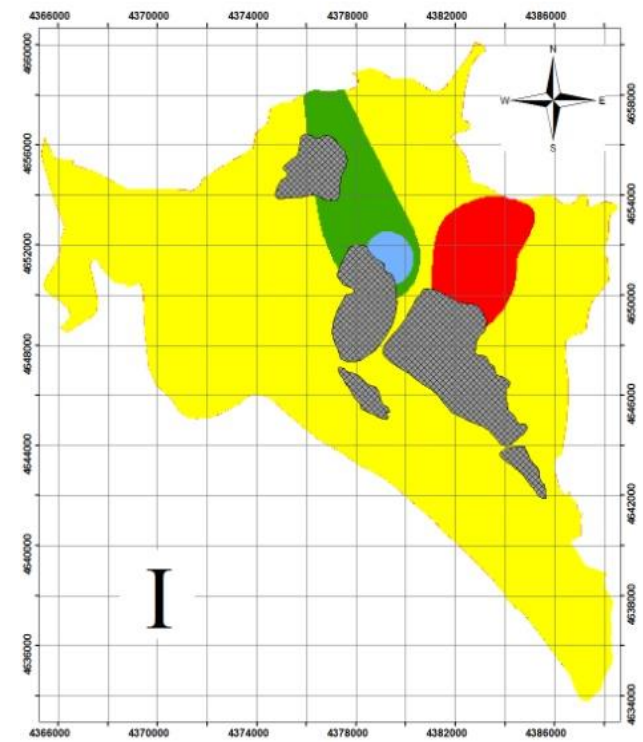

\begin{tabular}{|l|l|l|}
\hline $\begin{array}{c}\text { Material of the } \\
\text { vadose zone }\end{array}$ & Rating & Shading \\
\hline Gravel & 8 & \\
\hline Clay-Sand-Gravel & 4 & \\
\hline Clay-Sand & 3 & \\
\hline Clay & 2 & \\
\hline
\end{tabular}

Figure 6 - Vadose zone media rating map.

\subsubsection{Hydraulic Conductivity of the aquifer (C)}

Hydraulic conductivity values are associated with the properties of aquifers that determine the flow of groundwater in the area of saturation. Hydraulic conductivity data are assessed during test pumping. In the study area they range from $12 \mathrm{~m} /$ day to more than $81 \mathrm{~m} /$ day. The distribution of variable $\mathrm{C}$ values are presented in Figure 7. 


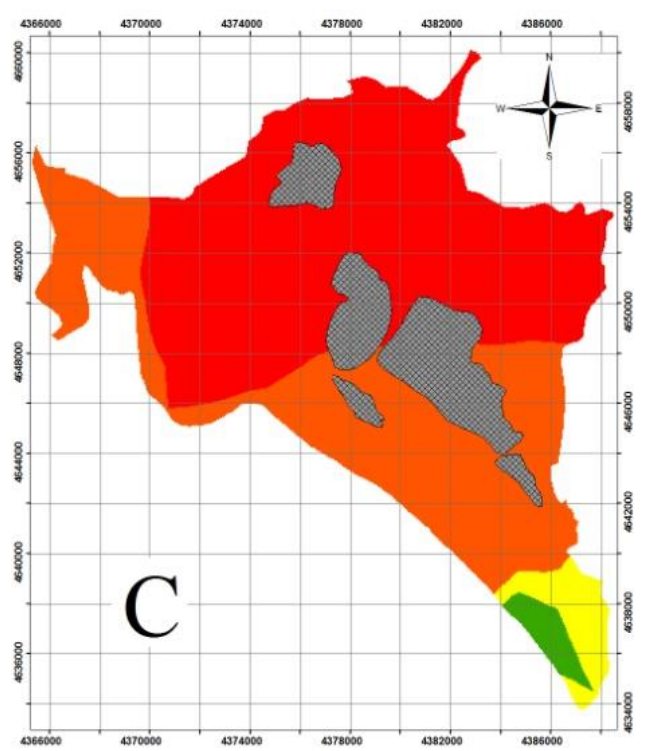

\begin{tabular}{|l|l|l|}
\hline $\begin{array}{c}\text { Hydraulic } \\
\text { conductivity } \\
\text { (m/day) }\end{array}$ & Rating & Shading \\
\hline$>82$ & 10 & \\
\hline $41-82$ & 8 & \\
\hline $29-41$ & 6 & \\
\hline $12-29$ & 4 & \\
\hline
\end{tabular}

Figure 7 - Hydraulic Conductivity rating map.

Table 2 - Values of the seven calculated parameters.

\begin{tabular}{|c|c|c|c|c|c|c|c|c|c|c|c|c|c|}
\hline \multicolumn{3}{|c|}{ 1. Depth to water } & \multicolumn{4}{|c|}{ 2. Net Recharge } & \multicolumn{2}{|c|}{ 3. Aquifer media } & & & \multicolumn{3}{|c|}{ 4. Soil media } \\
\hline $\begin{array}{ll}\text { Rangers } & \mathrm{R} \\
\end{array}$ & Ratings & Index & & Rangers & Ratings & Index & Aquifer & & Ratings & Index & \multicolumn{2}{|c|}{ Rangers } & $\mathrm{Ra}$ \\
\hline$(\mathrm{m})$ & (Dr) & (D) & & (mm/year) & (Dr) & (D) & & & (Dr) & (D) & & & \\
\hline$<4.5$ & 9 & 45 & & $>400$ & 10 & 40 & Gravel & & 8 & 24 & \multicolumn{2}{|c|}{ Medium textured } & \\
\hline $4.5-9$ & 7 & 35 & & $250-400$ & 9 & 36 & & & & & \multicolumn{2}{|c|}{ Fine textured } & \\
\hline $9--15$ & 5 & 25 & & $150-250$ & 8 & 32 & & & & & \multicolumn{2}{|c|}{ Very fine textured } & \\
\hline $15-23$ & 3 & 15 & & & & & & & & & & & \\
\hline $23-31$ & 2 & 10 & & & & & & & & & & & \\
\hline$>31$ & 1 & 5 & & & & & & & & & & & \\
\hline Weight: 5 & & & & & & & Weight: 3 & & & & Weight: 2 & & \\
\hline \multicolumn{4}{|c|}{ 5. Topography } & \multicolumn{5}{|c|}{ 6. Impact of the vadose zone } & & \multicolumn{4}{|c|}{ 7. Hydraulic Conductivity } \\
\hline Rangers & \multicolumn{2}{|c|}{ Ratings } & Index & \multicolumn{3}{|c|}{ Rangers } & Ratings & Index & & Rangers & Ratings & Index & \\
\hline (\%) & (D) & & (D) & & & & (Dr) & (D) & & m/day & (Dr) & (D) & \\
\hline \multirow[t]{4}{*}{$<2$} & \multicolumn{2}{|c|}{9} & 9 & \multicolumn{3}{|c|}{ Gravel } & 8 & 40 & & $>82$ & 10 & 30 & \\
\hline & & & & \multicolumn{3}{|c|}{ Clay-Sand-Gravel } & 4 & 20 & & $41-82$ & 8 & 24 & \\
\hline & & & & \multicolumn{3}{|c|}{ Clay-Sand } & 3 & 15 & & $29-41$ & 6 & 18 & \\
\hline & & & & \multicolumn{3}{|c|}{ Clay } & 2 & 10 & & $12--29$ & 4 & 12 & \\
\hline Weight: 1 & & & & \multicolumn{3}{|c|}{ Weight:5 } & & & & Weight: 3 & & & \\
\hline
\end{tabular}

\subsection{DRASTIC vulnerability index}

The values of the DRASTIC vulnerability indicator in the study area range from 109 to 180 . These values have been classified into two classes: The class with high vulnerability (140-180) and the class with average vulnerability (100-140). The map of the porous vulnerability of the VelipojaZadrima aquifers is shown in figure 8 . About $169 \mathrm{~km}^{2}$ or $71 \%$ of the surface of the aquifer is included in the class with a high vulnerability; the rest of the aquifer ( $29 \%$ of it) is included in the class with average vulnerability. 


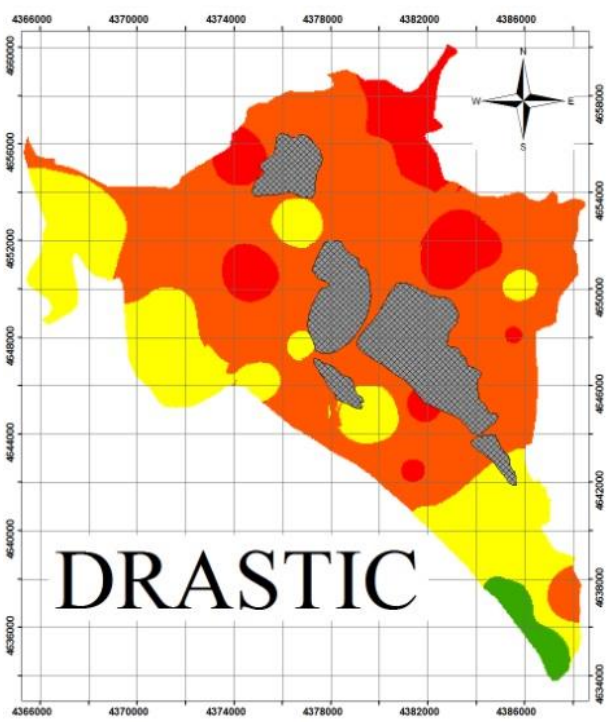

\begin{tabular}{|c|c|c|}
\hline \multicolumn{3}{|c|}{ Vulnerability Degrees } \\
\hline $\mathbf{H}$ & $\mathbf{M}$ & $\begin{array}{c}\text { DRASTIC } \\
\text { Values }\end{array}$ \\
\hline & & $160-180$ \\
\hline & & $140-160$ \\
\hline & & $120-140$ \\
\hline & & $100-120$ \\
\hline
\end{tabular}

H=High $\quad \mathbf{M}=$ Medium

Figure 8 - Vulnerability map of the Velipoja-Zadrima aquifer.

\subsection{Conclusions}

The DRASTIC index has been used for the natural vulnerability assessment of groundwater pollution in the porous aquifer of Velipoja-Zadrime. Average values of vulnerability represent a small area and lie in the northwestern and southeastern parts of the study area. In the larger area of the aquifer, about $71 \%$, high vulnerability values are present.

The results shown in the map of vulnerability contain important data for groundwater management bodies (local and central authorities). This map is needed for the integrated management of groundwater resources of the territory. The vulnerability map is also necessary for mapping the areas of groundwater protection.

In the future, the investigation of the natural vulnerability of groundwater in the Velipoja-Zadrima aquifer should be improved through the application of geophysical measurements, computational modelling of the simulation of groundwater flow, net food and improved monitoring methods.

\subsubsection{Discussion}

The study of pollution vulnerability with the DRASTIC method helped to establish two classes of vulnerability respectively, average and high.

This method is used to create a more accurate idea of the sensitive areas in this region in order to take necessary protective measures.

The model parameters, such as land and water depth, are based on relatively limited data. In future studies, the accuracy of the data in the local area is very important for the assessment, more detailed and robust data will yield better results. Also, sensitivity analysis of the parameters is necessary in assessment vulnerability.

In the future it is better to compare the DRASTIC methods again to the methods used in the valuation of assessing the vulnerabilitety of groundwater water. 


\section{References}

Aller, L., Bennet, T., Lehr, J.H. and Petty, R.J., 1987. DRASTIC: A standardized system for evaluating groundwater pollution potential using hydrogeologic settings, U.S. EPA Report, 600/2-85/018.

Babameto, A., 1968. Report on the results of the hydrogeological works performed during 1968 in the districts of Shkodra-Lezha-Durres and Fieri, G.S.A Archive.

Beshku, H., 2012. Hydrogeological Report of Buna basin in Albania, GEF-UNEP-MAP Med Partnership Project, Activity 1.1. 2. 2. Integration of groundwater and coastal aquifer management in ICZM and IWRM planning systems, Environment Ministry's Archive, Tiranë.

Beshku, H., 2012b. Report on "Assessment of Risk and Uncertainty related to Coastal Aquifers Management in Albania: UNESCO-IHP Sub-component 1.1 on "Managing Coastal Aquifer and Groundwater" of the GEF UNEP/MAP "Strategic Partnership for the Mediterranean Sea Large Marine Ecosystem (MedPartnership)", Environment Ministry's Archive, Tiranë.

Beshku, H., Pambuku, A. and Avxhi, A., 2014. Annual Report of Albania hydrogeological map in scale 1:200 000 .

Civita, M., 1994. Le carte della vulnerabilita degli acquferi all' inqunamento. Teoria and practica. (Aquifer pollution vulnerability maps), Pitatora $E d$., Bologna (in Italian).

Gelaj, A, Gjivogli, G. and Mamaj, A., 2001. The assessment and possibility of increasing the exploitable groundwater reserves in Albania and defining the terms of their rational use (the region of Shkodra, Lushnje area of Burrel and the Bulqiza-Bishop). Scale 1:50 000, A.G.S Archive.

Gjata, A., Lako, A., Romeo, E. and Tyli, N., Report on geological surveying works in 1964.

Gjata, A., Lako, A., Eftimi, R. and Tyli, N., 1965. Hydrogeology of Tirane-Koplik area, Central Archive of AGS, Tirana (in Albanian).

Hoxha, J., Kuliçi, H. and Cara, F., 2009. Quaternary deposits in the geological structures of Albanides, UPT, Inst. Geosciences, Tirana, 201-213.

Keta, Z., Babameto, A. and Haxhia, P., 1988. Project on the complex mapping at the scale 1: 25.000 of Bregu I Bunes-Fusha Zadrimes-Velipoje-Lezhe, Central Archive of AGS, Tirana (in Albanian).

Margat, J., 1968. Groundwater vulnerability to contamination, Publication 68, BRGM, Orleans, France.

Sener, E., Sener, S. and Davraz, A., 2009. Assessment of aquifer vulnerability based on GIS and DRASTIC methods: a case study of the Senirkent-Uluborlu basin (Isparta, Turkey). Hydrogeology Journal, 17, 2023-2035.

Tülin, N., 1988. Report on the water supply to the villages of Shirq, Samrish, Dajçivjeter, Trush, Plepan, Mount Jushi, Oblike e re, A.G.S archive.

Vrba, J. and Zaporozec, A., 1994.Guidebook on mapping groundwater vulnerability, Heise.

Voudouris, K., Kazakis, N., Polemio, M. and Kareklas, K., 2010. Assessment of Intrinsic Vulnera bility usinf the DRASTIC Model and GIS in the KITI Aquifer, Cyprus, European Water, 30, 13-24, 2010. 